\title{
Collapse phenomenon during Chartis collateral ventilation assessment
}

\author{
Wolfgang Gesierich ${ }^{1,4}$, Konstantinos Samitas ${ }^{1,2,4}$, Frank Reichenberger ${ }^{1}$ and \\ Juergen Behr ${ }^{1,3}$
}

Affiliations: ${ }^{1}$ Klinik für Pneumologie, Asklepios Fachkliniken, Gauting, Comprehensive Pneumology Center Munich (CPC) and Member of the German Center for Lung Research (DZL), Germany. ${ }^{27 t h}$ Respiratory Dept and Asthma Center, Athens Chest Hospital "Sotiria", Athens, Greece. ${ }^{3}$ Dept of Internal Medicine V, University of Munich, Munich, Germany. ${ }^{4}$ These authors contributed equally to this work.

Correspondence: Wolfgang Gesierich, Asklepios Fachkliniken Munich-Gauting, Robert-Koch-Allee 2, 82131 Gauting, Germany. E-mail: w.gesierich囚asklepios.com

ABSTRACT Chartis is increasingly used for bronchoscopic assessment of collateral ventilation before endobronchial valve (EBV) treatment for severe emphysema. Its prognostic value is, however, limited by the airway collapse phenomenon. The frequency and clinical significance of the collapse phenomenon remain largely unknown.

We performed a retrospective analysis of 92 patients undergoing Chartis evaluation under spontaneous breathing $(n=55)$ or jet ventilation $(n=37)$ from May 2010 to November 2013. Collateral ventilation status (positive/negative/collapse phenomenon/unclear) was reassessed and correlated with high-resolution computed tomography (HRCT) fissure analysis and clinical response.

In the absence of the collapse phenomenon, the predictive value of Chartis measurements and HRCT fissural analysis was comparable. The collapse phenomenon was observed in $31.5 \%$ of all assessments, and was more frequent in lower lobes (44.9\% versus $16.9 \%$ in upper lobes) and under jet ventilation $(41.4 \%$ versus $22.1 \%$ under spontaneous breathing). $69.8 \%$ of lobes with the collapse phenomenon had complete fissures. Most patients with the collapse phenomenon in the target lobe and complete fissures treated with EBVs were responders $(n=11 / 15)$. All valve-treated collapse phenomenon patients with fissure defects were nonresponders $(n=3)$.

In the absence of the collapse phenomenon Chartis measurement is reliable to predict response to valve treatment. In patients with the collapse phenomenon, treatment decisions should be based on HRCT detection of fissure integrity. Chartis assessment should be performed under spontaneous breathing.

@ERSpublications

Collapse phenomenon during Chartis assessment of collateral ventilation is frequent: fissure analysis should be added http://ow.ly/Y76Ej

Editorial comment in Eur Respir J 2016; 47: 1606-1610.

This article has supplementary material available from erj.ersjournals.com

Received: Nov 252015 | Accepted after revision: Jan 252016 | First published online: April 132016

Conflict of interest: Disclosures can be found alongside the online version of this article at erj.ersjournals.com

Copyright OERS 2016 


\section{Introduction}

In the last decade bronchoscopic lung volume reduction (BLVR) using endobronchial valves (EBVs) has emerged as a new treatment option for severe emphysema [1]. The safety and effectiveness of EBVs has been shown in the VENT (Endobronchial Valve for Emphysema Palliation Trial) studies, which have, however, also demonstrated that response to treatment is not uniform for all EBV-treated patients $[2,3]$. Collateral ventilation emerged as the most important factor impeding the effect of EBVs and became a key issue during patient selection.

Interlobar fissures are frequently incomplete in healthy individuals $[4,5]$ and emphysema patients $[6-8]$ as parenchymal bridges exist between neighbouring lobes. Airway obstruction and breakdown of pulmonary parenchyma in emphysema promotes airflow via these bridges, refilling the valve-occluded target lobe and preventing volume reduction [9]. A retrospective analysis of the VENT study revealed that fissure completeness, assessed by high-resolution computed tomography (HRCT), is a major prerequisite for treatment effectiveness [2, 3]. The BeLieVeR-HIFi study has recently verified that EBV treatment significantly improves lung function in selected patients with intact interlobar fissures [10].

In recent years, the Chartis Pulmonary Assessment System has become available to directly measure interlobar collateral ventilation during bronchoscopy $[11,12]$. Chartis consists of a balloon catheter and a console with flow and pressure sensors. The balloon catheter is placed in the target lobe orifice to block the airway and direct airflow through its central lumen. A valve mechanism in the console allows only for expiratory flow, simulating the situation of complete valve occlusion of the target lobe. Continuous expiratory flow for $>5 \mathrm{~min}$ (or when the total exhaled volume exceeds $1 \mathrm{~L}$ ) suggests refilling of the lobe through collateral channels, whereas gradual decline and eventual cessation of flow points to the absence of collateral ventilation [1].

Chartis has been prospectively assessed in earlier studies, showing an accuracy of $75 \%$ in predicting response to EBV treatment, and seems to correlate with fissure analysis [13-15]. A recent prospective study has demonstrated significant improvement in pulmonary function and exercise capacity after EBV treatment in emphysema patients with absence of interlobar collateral ventilation evidenced by Chartis assessment [16]. Broad clinical use has, however, demonstrated that the dynamic expiratory airway collapse in emphysema can lead to a sudden stop of flow during Chartis assessment, rendering the measurement inconclusive $[17,18]$. The clinical significance of this "low-flow" or "collapse" phenomenon remains elusive, as it has not been documented in earlier studies. Accurate assessment of collateral ventilation before EBV placement becomes even more important as collateral ventilation-independent treatment alternatives increasingly emerge [19-21].

Our centre has extensive experience with Chartis, as it has been our method of choice for the assessment of collateral ventilation prior to BLVR since May 2010. We performed a retrospective analysis of 92 consecutive patients evaluated with Chartis for EBV placement in order to assess the frequency and distribution of the collapse phenomenon in a "real-life" clinical routine setting. We evaluated whether the mode of ventilation (spontaneous breathing versus jet ventilation) during the assessment of collateral ventilation influences Chartis outcomes. We also investigated how Chartis outcomes, especially the collapse phenomenon, correlate with conventional, visual HRCT-based fissure analysis. Finally, we analysed the significance of the collapse phenomenon with respect to clinical outcome.

\section{Methods}

\section{Patient population}

92 consecutive patients assessed with Chartis in our Institution (Asklepios Fachkliniken) from May 2010 to November 2013 were identified for retrospective analysis. The patients had been referred to our hospital for evaluation of BLVR. They suffered from severe emphysema, as evidenced by HRCT scans, severe airway obstruction (forced expiratory volume in $1 \mathrm{~s}$ (FEV 1 )/forced vital capacity (FVC) $<70 \%$ and FEV 1 $<50 \%$ predicted), hyperinflation (residual volume (RV) $>160 \%$ predicted) and relevant dyspnoea (modified Medical Research Council (mMRC) scale $\geqslant 1$ ) despite adequate standard therapy [22]. Patient characteristics are summarised in table 1. All patients were free of symptoms of active pulmonary infection and did not have a chronic obstructive pulmonary disease exacerbation 2 months prior to evaluation for EBV placement. The retrospective patient analysis was approved by the Ethics Committee of Ludwig Maximilian University of Munich (UE-Nr 167-13). Written informed consent had been obtained from all patients during the clinical course of evaluation and endoscopic treatment for undergoing HRCT scanning and bronchoscopy with Chartis assessment and valve placement, if applicable.

\section{Baseline assessment}

Screening was performed prior to bronchoscopy in accordance with a standard procedure followed in our institution, comprising medical history, physical examination, dyspnoea evaluation by the mMRC scale [23], 


\begin{tabular}{|c|c|c|c|c|c|}
\hline & Total & $\mathrm{CV}+$ & CV- & $\mathrm{CP}$ & Unclear \# \\
\hline \multicolumn{6}{|l|}{ Demographics } \\
\hline Patients & 92 & 15 & 50 & 21 & 6 \\
\hline Age years & $66.9 \pm 6.3$ & $67.3 \pm 6.3$ & $66.7 \pm 6.4$ & $67.0 \pm 6.4$ & $66.7 \pm 7$ \\
\hline Female/male & $34 / 58$ & $4 / 11$ & $18 / 32$ & $9 / 12$ & $3 / 3$ \\
\hline \multicolumn{6}{|l|}{ Arterial blood gas } \\
\hline $\mathrm{PaO}_{2} \mathrm{mmHg}$ & $67.7 \pm 14$ & $62.1 \pm 8.4$ & $68.9 \pm 16.2$ & $66.7 \pm 9.7$ & $75 \pm 18.1$ \\
\hline $\mathrm{PaCO}_{2} \mathrm{mmHg}$ & $40.9 \pm 6.0$ & $39.8 \pm 6.3$ & $41.8 \pm 5.6$ & $38.4 \pm 5.3$ & $44.3 \pm 8.5$ \\
\hline $\mathrm{pH}$ & $7.43 \pm 0.03$ & $7.44 \pm 0.02$ & $7.42 \pm 0.03$ & $7.44 \pm 0.03$ & $7.44 \pm 0.03$ \\
\hline \multicolumn{6}{|l|}{ Lung function } \\
\hline $\mathrm{FEV}_{1} \mathrm{~L}$ & $0.87 \pm 0.27$ & $0.90 \pm 0.18$ & $0.84 \pm 0.26$ & $0.98 \pm 0.34$ & $0.76 \pm 0.07$ \\
\hline FEV $1 \%$ pred & $32.8 \pm 8.6$ & $33.7 \pm 7.5$ & $31.6 \pm 8.0$ & $36.7 \pm 10.1$ & $28.7 \pm 4.6$ \\
\hline$V C_{\max } \mathrm{L}$ & $2.23 \pm 0.72$ & $2.22 \pm 0.42$ & $2.14 \pm 0.76$ & $2.49 \pm 0.84$ & $2.05 \pm 0.48$ \\
\hline $\mathrm{VC}_{\max } \%$ pred & $63.0 \pm 14.3$ & $63.2 \pm 12.3$ & $60.4 \pm 15.2$ & $70.1 \pm 11.8$ & $59.9 \pm 13.5$ \\
\hline $\mathrm{FEV}_{1} / \mathrm{FVC}$ & $43.4 \pm 8.0$ & $43.5 \pm 7.1$ & $44.2 \pm 7.9$ & $42.9 \pm 9.0$ & $41.5 \pm 7.1$ \\
\hline$D \mathrm{LCO} \mathrm{mL} \cdot \mathrm{min}^{-1} \cdot \mathrm{mmHg}^{-1}$ & $2.19 \pm 0.90$ & $1.95 \pm 0.54$ & $2.02 \pm 0.6$ & $2.79 \pm 1.3$ & $1.7 \pm 0.37$ \\
\hline DLco \% pred & $25.9 \pm 10.1$ & $23.0 \pm 7.6$ & $23.8 \pm 7.0$ & $33.4 \pm 13.9$ & $20.9 \pm 5.3$ \\
\hline RV L & $5.98 \pm 1.45$ & $6.05 \pm 1.86$ & $6.08 \pm 1.29$ & $5.89 \pm 1.63$ & $5.29 \pm 1.24$ \\
\hline RV \% pred & $253 \pm 60$ & $251 \pm 60$ & $261 \pm 55.5$ & $237 \pm 72$ & $243 \pm 65$ \\
\hline TLC L & $8.16 \pm 1.63$ & $8.26 \pm 2.14$ & $8.2 \pm 1.45$ & $8.23 \pm 1.80$ & $7.27 \pm 1.12$ \\
\hline TLC \% pred & $134 \pm 23$ & $134 \pm 24$ & $138 \pm 19$ & $130 \pm 31$ & $126 \pm 25$ \\
\hline \multicolumn{6}{|l|}{ Exercise performance and quality of life } \\
\hline 6MWT m & $306 \pm 101$ & $304 \pm 100$ & $301 \pm 101$ & $328 \pm 113$ & $258 \pm 49$ \\
\hline SGRQ & $61 \pm 14$ & $60 \pm 16$ & $63 \pm 15$ & $57 \pm 12$ & $67 \pm 9$ \\
\hline $\begin{array}{l}\text { Ventilation during Chartis measurement } \\
\text { spontaneous/mechanical }\end{array}$ & $55 / 37$ & $11 / 4$ & $28 / 22$ & $11 / 10$ & $5 / 1$ \\
\hline
\end{tabular}

Data are presented as $\mathrm{n}$ or mean $\pm \mathrm{SD}$. $\mathrm{CV}+$ : positive collateral ventilation phenotype; $\mathrm{CV}$-: negative collateral ventilation phenotype; $\mathrm{CP}$ : collapse phenomenon phenotype; $\mathrm{PaO}_{2}$ : arterial oxygen tension; $\mathrm{PaCO}_{2}$ : arterial carbon dioxide tension; FEV1: forced expiratory volume in $1 \mathrm{~s}$; VCmax: maximum vital capacity; FVC: forced vital capacity; DLCo: diffusing capacity of the lung for carbon monoxide; RV: residual volume; TLC: total lung capacity; 6MWT: 6-min walk test; SGRQ: St George's Respiratory Questionnaire. \#: five patients were categorised as unclear, one patient did not complete the procedure due to upper airway collapse during the measurement under sedation and spontaneous ventilation. No significant differences were observed between groups (Kruskal-Wallis test).

quality of life assessment by the St George's Respiratory Questionnaire (SGRQ) [24], echocardiogram, post-bronchodilator spirometry [25], lung volume measurements by body plethysmography [26], 6-min walk test (6MWT) [27], chest radiograph, HRCT and ${ }^{99 \mathrm{~m}} \mathrm{Tc}$ macro-aggregated albumin perfusion scintigraphy.

\section{HRCT imaging and fissure analysis}

Available HRCT scans were reviewed for image quality using a DICOM work station (Synedra View Professional 3.2.0.15; Synedra Information Technologies, Innsbruck, Austria) and accepted for fissure analysis if axial images with slice thickness $<2 \mathrm{~mm}$ were available for multiplanar reconstruction. For the purpose of this analysis, the right oblique fissure was separated in two parts: the upper part between the right upper and lower lobe, and the lower part between the right middle and lower lobe. Fissures were assessed visually on sagittal, coronal and axial sections, and described as complete when they could be visualised in their entirety separating two adjacent lobes at least in one plane. In incomplete fissures, the size of the defect was approximated by multiplying its largest diameter in two perpendicular planes (sagittal and coronal or axial), as previously described [28]. For lobes bordered by two different fissures, the total defect size was estimated by adding defect sizes of the two individual fissures. Representative examples of fissure analysis are shown in online supplementary figure E1.

\section{Chartis assessment of collateral ventilation}

Chartis assessment was performed during flexible bronchoscopy under local anaesthesia and sedation in spontaneously breathing patients from May 2010 to September 2012, as previously described [12]. Patients received local anaesthesia with up to $25 \mathrm{~mL}$ lidocaine $1 \%$, and sedation with 2.5-5 mg midazolam and additional repeated propofol boli of $20-40 \mathrm{mg}$ if necessary. With the intention to improve testing conditions, combined rigid/flexible bronchoscopy under general anaesthesia (using atropine, remifentanil, 
propofol and mivacurium) and jet ventilation was used after October 2012 (Mistral; Acutronic Medical Systems, Hirzel, Switzerland; respiratory frequency 15 breaths $\mathrm{min}^{-1}$, inspiratory pressure $150-250 \mathrm{kPa}$ ). The target lobe was identified by visual assessment of HRCT (lobe with the most severe emphysematous destruction) and perfusion scintigraphy (lobe with the lowest perfusion). Available Chartis reports were reanalysed and retrospectively categorised into four different phenotypes: positive collateral ventilation $(\mathrm{CV}+)$, negative collateral ventilation $(\mathrm{CV}-)$, collapse phenomenon $(\mathrm{CP})$ and unclear. Analysis was performed according to specific criteria established by our group and others (table 2) [1, 17, 18]. Representative Chartis output patterns are shown in figure 1.

\section{Endobronchial valves}

Valve implantation was performed during combined rigid-flexible bronchoscopy under general anaesthesia and jet ventilation. Zephyr valves (Pulmonx, Redwood City, CA, USA) were placed unilaterally in the target lobe on a segmental or subsegmental level on the basis of individual anatomy with the goal of complete occlusion, as previously described [29]. For the first 15 patients, valves were also implanted when the target lobe had been assessed as $\mathrm{CV}+$ by Chartis, as published data and clinical experience regarding Chartis were very limited at that time. Data from these patients were presented as a meeting abstract [30]. Based on this experience, valve treatment of $\mathrm{CV}+$ patients was later avoided.

\section{Clinical follow-up}

Follow-up was performed 3-6 months after endoscopic intervention, and included post-bronchodilator spirometry, body plethysmography, 6MWT, mMRC scale, SGRQ and chest radiographs. The clinical response of treated patients was assessed according to specific responder definition criteria using the principle of minimal clinical important difference [31]. Three or more of the following criteria had to be met by a patient treated with EBVs in order to be considered as a responder: $\Delta \mathrm{FEV} 1 \geqslant 12 \%$ or $100 \mathrm{~mL}[32,33], \Delta \mathrm{RV} \geqslant$ $-8 \%$ or $-400 \mathrm{~mL}$ [34], $\Delta \mathrm{VC}>12 \%, \Delta 6 \mathrm{MWT} \geqslant 27 \mathrm{~m}$ [35], $\Delta \mathrm{mMRC} \geqslant 1$ point [36], $\Delta \mathrm{SGRQ} \geqslant 4$ units [37] and, finally, presence of complete or partial atelectasis of the target lobe in the chest radiograph.

\section{Statistical analysis}

Normality of data sets was assessed using the D'Agostino-Pearson omnibus normality test. Two-group comparisons were performed using the nonparametric Mann-Whitney U-test, whereas three-group comparisons were performed using the nonparametric Kruskal-Wallis one-way ANOVA accompanied by Dunn's post hoc correction. Correlation coefficients were calculated using the nonparametric Spearman rank method. The accuracy of fissure analysis to discriminate between positive and negative collateral ventilation based on defect size was evaluated using receiver operating characteristic (ROC) curve analysis. Prism version 5 (GraphPad, San Diego, CA, USA) and MedCalc version 12 (MedCalc Software, Ostend, Belgium) statistical software packages were used for all data analysis and graph preparation. A p-value of $\leqslant 0.05$ was considered significant.

\section{Results}

\section{Patient population and baseline characteristics}

92 subjects, assessed by Chartis between May 2010 and November 2013, were identified and included in the retrospective analysis. 86 patients were successfully assessed with Chartis, and categorised as CV+,

\section{TABLE 2 Definition of different Chartis phenotypes}

Chartis phenotype Criteria

\begin{tabular}{ll}
\hline $\mathbf{C V}+[1]$ & Persistent airflow and: \\
& - Flow time $\geqslant 5 \mathrm{~min}$ or \\
CV- & TEV $\geqslant 1 \mathrm{~L}$ \\
& Gradual decrease and termination of airflow and: \\
& - Flow time $\geqslant 1 \mathrm{~min}$ and \\
CP [17] & TEV $\geqslant 50 \mathrm{~mL}$ \\
& Reproducible sudden termination of airflow and: \\
& - Flow time $<1 \mathrm{~min}$ or \\
Unclear & - TEV $<50 \mathrm{~mL}$
\end{tabular}

$\mathrm{CV}+$ : positive collateral ventilation; $\mathrm{CV}$-: negative collateral ventilation; $\mathrm{CP}$ : collapse phenomenon; TEV: total exhaled volume. 

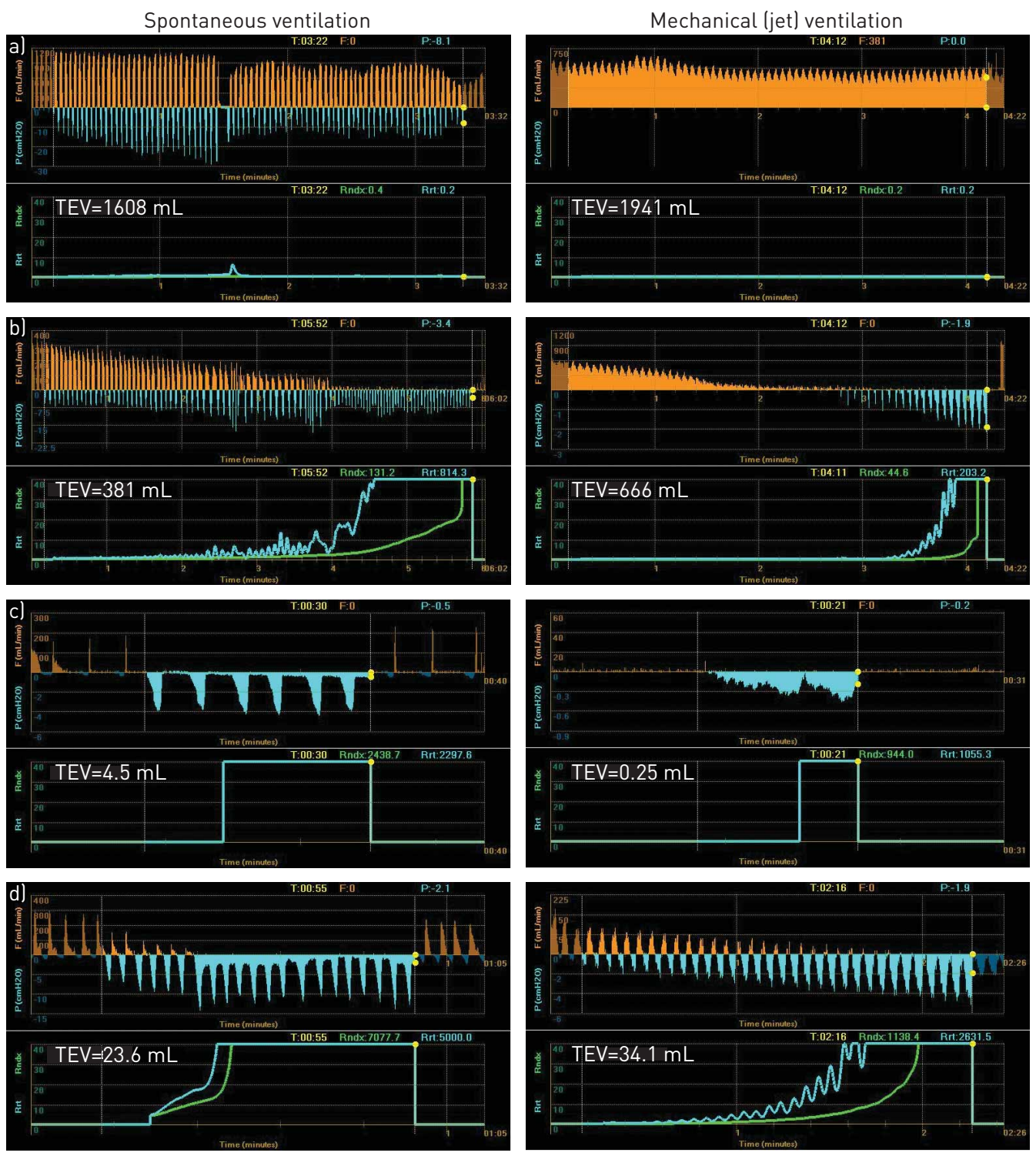

FIGURE 1 Representative output patterns for different Chartis phenotypes under spontaneous and mechanical ventilation. a) Positive collateral ventilation ( $C V+$ phenotype). Under spontaneous ventilation flow exists during expiration but stops during inspiration and negative pressure in the target lobe can be detected through the catheter. Under mechanical ventilation there is continuous expiratory flow throughout the measurement. Positive pressure during inspiration inflates the neighbouring lobe(s), compressing the occluded target lobe. Consequently, the expiratory flow is slightly increased during the inspiratory phase of the ventilator. Superimposition of these two phenomena leads to a saw-tooth pattern of the Chartis flow signal in mechanical ventilation. Throughout the entire measurement there is persistent flow and resistance remains low. Total exhaled volume exceeds the threshold of $1 \mathrm{~L}$ usually rather quickly. b) Negative collateral ventilation (CV- phenotype). At the beginning the Chartis signal resembles the $\mathrm{CV}+$ phenotype under both spontaneous and mechanical ventilation. During the assessment there is a gradual decrease and eventual cessation of flow, while resistance gradually rises to infinity. Total exhaled volume (TEV) exceeds the threshold of $50 \mathrm{~mL}$. c) Collapse phenomenon. Poor flow signal is detected upon placing the balloon in the orifice of the target lobe. Once the measurement is activated there is a sudden stop of flow and resistance suddenly increases to infinity. d) Delayed collapse phenomenon. Although a variably short period of flow is detected, total exhaled volume does not exceed the threshold of $50 \mathrm{~mL}$, rendering the assessment inconclusive, as it reflects a delayed dynamic airway collapse rather than true absence of collateral ventilation.

$\mathrm{CV}$ - and $\mathrm{CP}$ in the target lobe. Six patients were categorised as unclear because they did not meet any of the criteria set for these three groups. A study flow diagram is shown in figure 2. As shown in table 1, no significant differences were observed between groups with respect to demographic data, pulmonary function, exercise capacity and quality of life at baseline. 


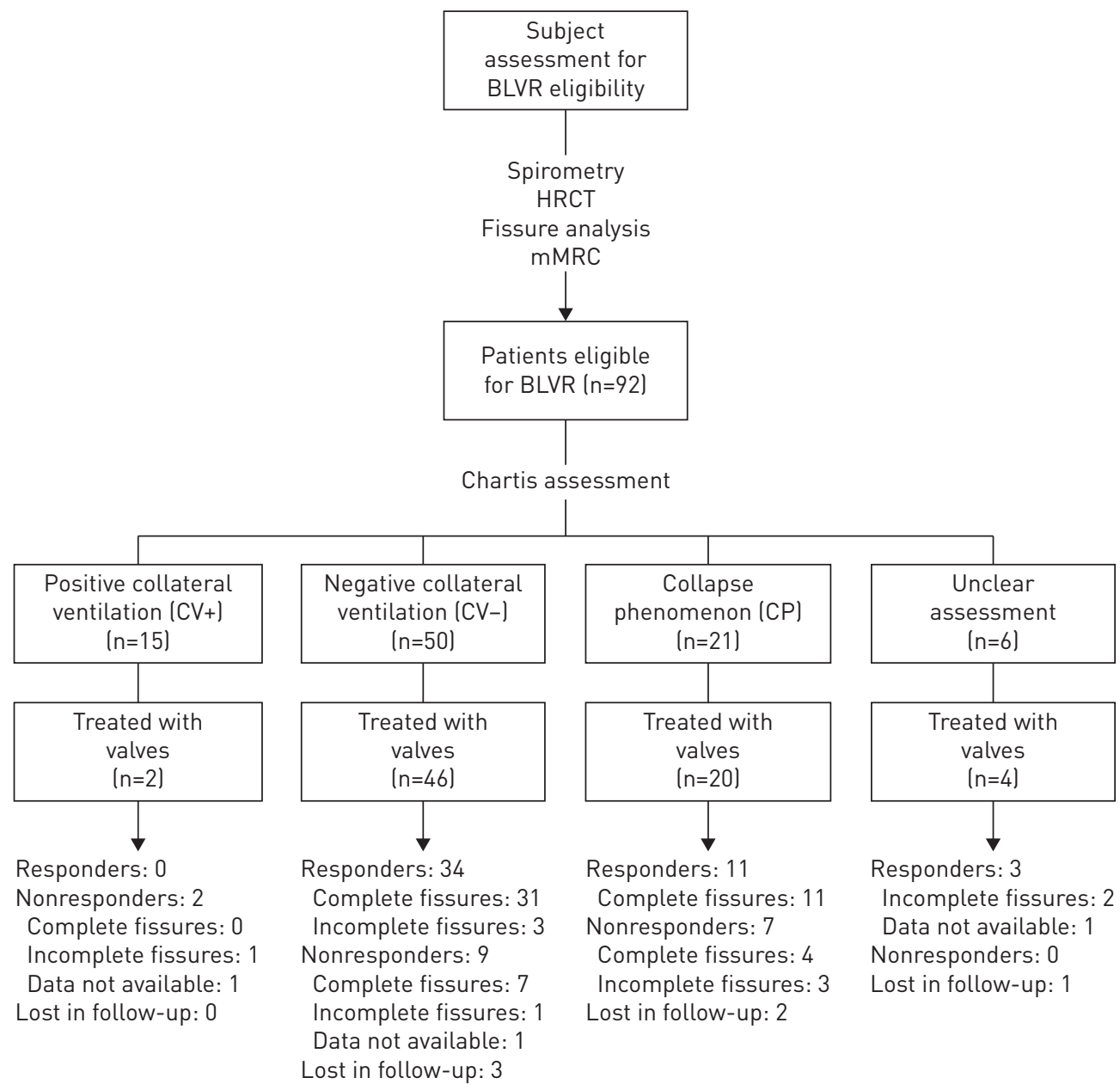

FIGURE 2 Flow diagram showing patient groups and procedures. Patients referred to our Institution for evaluation underwent spirometry, high-resolution computed tomography (HRCT) and fissure analysis, and selected patients eligible for bronchoscopic lung volume reduction (BLVR) underwent Chartis-assisted evaluation of collateral ventilation prior to endobronchial valve treatment and were categorised using specific criteria into four phenotypes: CV+ (positive collateral ventilation), CV- (negative collateral ventilation), CP (collapse phenomenon) and unclear. mMRC: modified Medical Research Council dyspnoea scale.

\section{HRCT fissure analysis}

HRCT scans were available at adequate quality for retrospective analysis in 85 subjects. The distribution and quantification of total defect size in single fissures and whole lobes are presented in online supplementary table E1. Fissural defects were most prevalent in the right horizontal fissure, followed by the right oblique and left oblique fissures. Accordingly, the prevalence and size of fissural defects decreased from the right upper lobe to the middle lobe, right lower lobe and left-side lobes.

\section{Chartis analysis and frequency of the collapse phenomenon}

149 lobes were assessed in 92 patients. Chartis results corresponding to individual lobes are presented in table 3. Correlating with the frequency distribution of fissural defects, the $\mathrm{CV}+$ phenotype was more frequent on the right, especially in the upper lobe, whereas the CV- phenotype was more frequent on the left.

The CP phenotype was found in $31.5 \%$ of all assessments and was considerably more frequent in the lower lobes compared with the upper lobes in both the right and left lung (40.6\% versus 10.7\% and $47.8 \%$ versus $22.5 \%$, respectively). Interestingly, all patients $(n=9)$ that exhibited the collapse phenomenon in the left upper lobe also presented the collapse phenomenon in the left lower lobe. Furthermore, out of the 22 patients with the collapse phenomenon in the left lower lobe, 10 also presented the collapse phenomenon in the left upper lobe, while only four patients were categorised as CV+ or CV-, and one in the unclear group. Assessment of the left upper lobe was not available in seven of these patients. 
TABLE 3 Chartis results corresponding to the lobes being targeted

\begin{tabular}{lcccc} 
& CV+ & CV- & CP & Unclear \\
\hline Measurements & 30 & 57 & 47 & 15 \\
Right upper lobe & $14(50)$ & $8(28.6)$ & $3(10.7)$ & $3(10.7)$ \\
Right middle lobe & $0(0)$ & $1(33.3)$ & $0(0)$ & $2(66.7)$ \\
Right lower lobe & $4(12.5)$ & $10(31.3)$ & $13(40.6)$ & $5(15.6)$ \\
Left upper lobe & $8(20.0)$ & $20(50.0)$ & $9(22.5)$ & $3(7.5)$ \\
Left lower lobe & $4(8.7)$ & $18(39.1)$ & $22(47.8)$ & $2(4.4)$ \\
TEV mL & $853 \pm 81^{\#, 9}$ & $231 \pm 21$ & $24 \pm 2.5^{+}$ & $224 \pm 50$ \\
Duration s & $279 \pm 9^{\S}$ & $230 \pm 17$ & $50 \pm 8^{f}$ & $122 \pm 23$ \\
Ventilation spontaneous/mechanical & $22 / 8$ & $31 / 26$ & $17 / 29$ & $7 / 8$ \\
\hline
\end{tabular}

Data are presented as $\mathrm{n}, \mathrm{n}(\%)$ or mean \pm SEM. $\mathrm{CV}+$ : positive collateral ventilation phenotype; $\mathrm{CV}$-: negative collateral ventilation phenotype; CP: collapse phenomenon phenotype; TEV: total exhaled volume. Statistical analysis between groups was performed by one-way ANOVA (Kruskal-Wallis). \#: $p<0.001$ compared with CV- and $C P ;{ }^{\uparrow}: p<0.01$ compared with unclear; ${ }^{+}: p<0.001$ compared with $C V$ - and unclear; $\S_{\text {: }} p<0.001$ compared with $C P$ and unclear; ${ }^{f}: p<0.001$ compared with $C V-$.

\section{Influence of ventilation mode on the Chartis result}

The CP phenotype was almost twice as frequent in jet-ventilated patients as compared with those breathing spontaneously ( $41.4 \%$ versus $22.1 \%$, respectively, $\mathrm{p}<0.05$; figure $3 \mathrm{a}$ ). Correspondingly, there were less definitive $(\mathrm{CV}+$ or $\mathrm{CV}-$ ) Chartis outcomes in jet-ventilated patients (28.6\% versus $11.4 \%$ for $\mathrm{CV}+$, $\mathrm{p}<0.05$ and $40.3 \%$ versus $37.1 \%$ for $\mathrm{CV}$-, respectively; figure $3 \mathrm{a}$ ). This shift was more pronounced in the lower lobes (CP phenotype $54.3 \%$ versus $34.1 \%$; definitive Chartis results $31.4 \%$ versus $60.9 \%$, respectively; figure $3 \mathrm{~b}$ ) compared with the upper lobes (CP phenotype $29.4 \%$ versus $13.9 \%$; definitive Chartis results $64.7 \%$ versus $77.7 \%$ respectively; figure $3 \mathrm{c}$ ). As shown in online supplementary table E2, patients in the spontaneous breathing group were slightly less hyperinflated at baseline compared with the mechanical ventilation group. Otherwise, no significant differences were observed between baseline characteristics of these two groups.
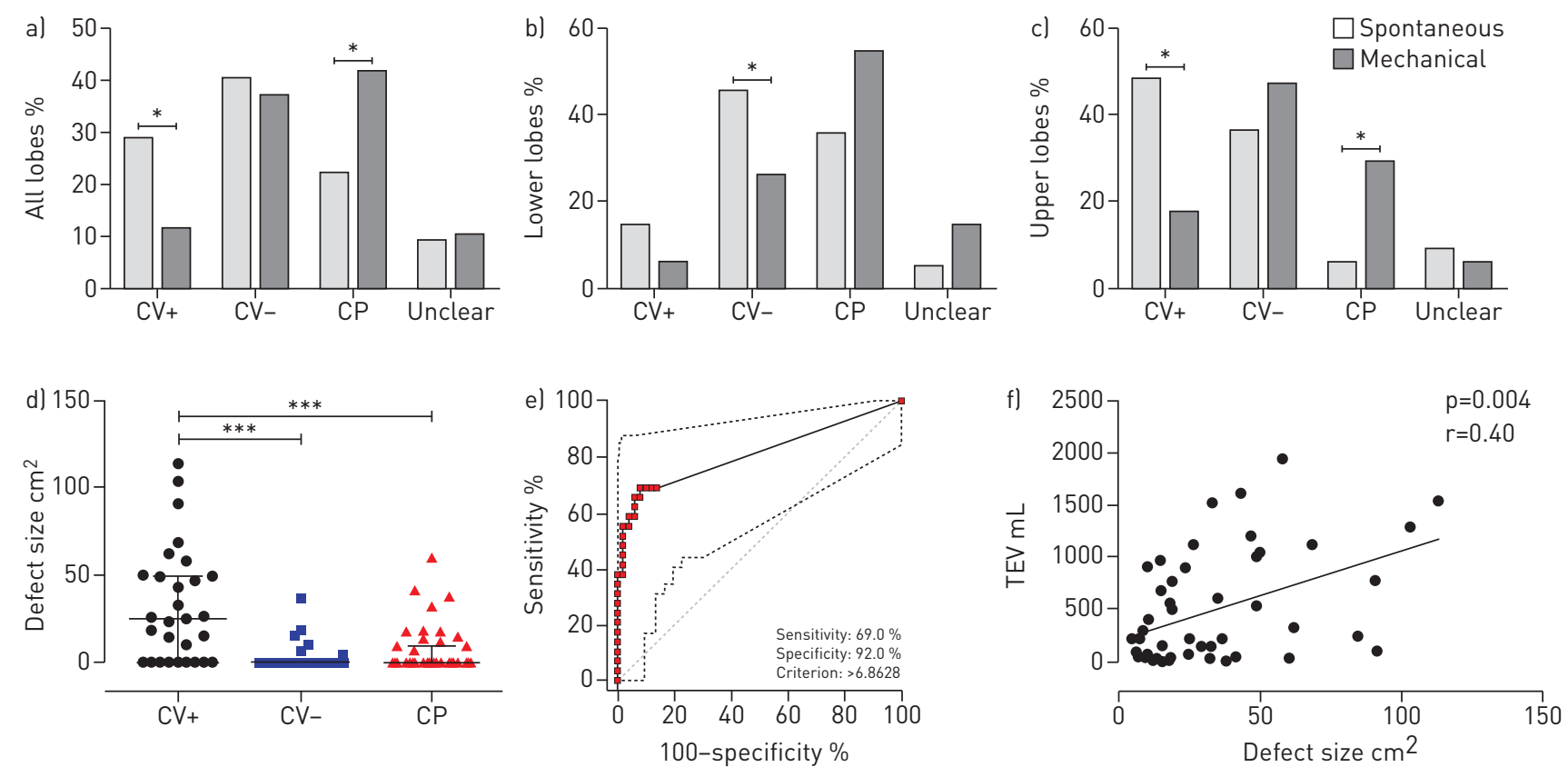

FIGURE 3 Effects of ventilation mode on Chartis outcomes and correlation with fissure analysis. The frequency of Chartis phenotypes depending on the ventilation mode is depicted for al all lobes, b) lower lobes and c) upper lobes, where it is demonstrated that the collapse phenomenon outcomes are increased under mechanical ventilation $(n=70)$ versus spontaneous ventilation $(n=77)$, mainly at the expense of $C V+$ outcomes. $C V+$ : positive collateral ventilation phenotype; CV-: negative collateral ventilation phenotype; CP: collapse phenomenon phenotype. d) Fissural defects are significantly increased in CV+ lobes compared with both CV- and CP lobes. The plots represent median with interquartile range. e) Receiver operating characteristic curve analysis demonstrates a fissure defect cut-off point of $6.8 \mathrm{~cm}^{2}$ over which Chartis measurements are more likely to result in a CV+ outcome. f) The size of fissural defects positively correlates with the total exhaled volume (TEV) measured during Chartis assessment. ${ }^{*}: p<0.05 ;{ }^{* * *}: p<0.0001$. 
TABLE 4 Comparison of Chartis phenotype with fissure analysis in 85 patients with available high-resolution computed tomography scans, corresponding to a total of 139 lobes

\begin{tabular}{lcccc} 
Fissures & CV+ & CV- & CP & Unknown \\
\hline Incomplete & 20 & 7 & 13 & 7 \\
Complete & 9 & 47 & 30 & 6
\end{tabular}

$\mathrm{CV}+$ : positive collateral ventilation phenotype; $\mathrm{CV}$-: negative collateral ventilation phenotype; $\mathrm{CP}$ : collapse phenomenon phenotype.

\section{Correlation between Chartis and fissure analysis}

The association between Chartis outcomes and corresponding fissure analysis for all 85 patients with available HRCT scans, representing a total of 139 lobes, is summarised in table 4. The majority of lobes with a CP phenotype $(69.8 \%)$ had complete fissures. Fissural defects were significantly increased in CV+ (mean \pm SEM $\left.31.8 \pm 6 \mathrm{~cm}^{2}\right)$ as compared with both CV- $\left(1.8 \pm 0.8 \mathrm{~cm}^{2}, \mathrm{p}<0.001\right)$ and CP lobes $\left(6.7 \pm 2 \mathrm{~cm}^{2}, \mathrm{p}<0.001\right.$; figure $3 d)$. Furthermore, for definitive Chartis outcomes (CV+ or $\mathrm{CV}-$ ), a strong correlation $(\mathrm{p}<0.0001, \mathrm{r}=0.61)$ was observed with fissure analysis. Nevertheless, there were seven lobes designated as $\mathrm{CV}$ - with incomplete fissures and nine lobes designated as $\mathrm{CV}+$ with complete fissures. A ROC analysis was performed to determine a fissure defect cut-off point over which Chartis measurements were more likely to result in a CV+ outcome (figure 3e). A cut-off gap value of $6.8 \mathrm{~cm}^{2}$ was identified, discriminating between the CV- and CV+ phenotypes with a sensitivity of $69 \%$ and specificity of $92 \%(\mathrm{p}<0.001$, area under the curve $0.811,95 \% \mathrm{CI}$ 0.708-0.891). Moreover, a modest correlation was also observed between the size of fissural defects and the total exhaled volume during Chartis assessment ( $\mathrm{p}=0.004, \mathrm{r}=0.40$; figure $3 \mathrm{f}$ ).

\section{Correlation with clinical outcome}

72 patients in our cohort were treated with valves (figure 2), with a mean (range) of 3.5 (2-6) valves needed to achieve complete lobar occlusion. Follow-up data were available in 66 patients (table 5).

18 patients had the collapse phenomenon in the target lobe. 11 of these 18 patients $(61 \%)$ responded to EBV treatment, all having complete fissures. Seven were nonresponders, and three of these had incomplete fissures with defect sizes of $60.1,18.3$ and $6.9 \mathrm{~cm}^{2}$.

43 patients were $\mathrm{CV}$ - in the target lobe. 34 of these 43 patients (79\%) responded to treatment (three having incomplete fissures with defect sizes of $15.9,6.0$ and $4.3 \mathrm{~cm}^{2}$ ) and nine remained nonresponders (one having incomplete fissures with a defect size of $6.9 \mathrm{~cm}^{2}$ ).

TABLE 5 Clinical outcomes between 3 and 6 months in endobronchial valve (EBV)-treated patients stratified by Chartis phenotype

\begin{tabular}{lcccc} 
& CV+ & CV- & CP & Unclear \\
\hline Patients & 15 & 50 & 21 & 6 \\
Treated with EBVs & 2 & 46 & 20 & 4 \\
Responders & 0 & 34 & 11 & 3 \\
Nonresponders & 2 & 9 & 7 & 0 \\
Lost to follow-up & 0 & 3 & 2 & 1 \\
$\Delta$ FEV 1 L & $-0.005 \pm 0.20$ & $0.16 \pm 0.03$ & $0.14 \pm 0.05$ & $0.035 \pm 0.07$ \\
$\Delta$ FEV $\%$ pred & $-0.52 \pm 18.0$ & $21.6 \pm 3.7$ & $13.9 \pm 4.5$ & $3.7 \pm 10.4$ \\
$\Delta$ VCmax L & $-0.01 \pm 0.13$ & $0.31 \pm 0.08$ & $0.15 \pm 0.13$ & $0.27 \pm 0.29$ \\
$\Delta$ VCmax \% pred & $-0.015 \pm 5.2$ & $17.5 \pm 4.4$ & $8.8 \pm 5.3$ & $9.3 \pm 14.2$ \\
$\Delta$ RV L & $0.27 \pm 0.54$ & $-0.81 \pm 0.17$ & $-0.46 \pm 0.21$ & $-0.64 \pm 0.63$ \\
$\Delta$ RV \% pred & $3.4 \pm 8.1$ & $-12.2 \pm 2.5$ & $-8.8 \pm 3.6$ & $-8.7 \pm 11.8$ \\
$\Delta$ 6MWT m & $45 \pm 25$ & $31.7 \pm 17.3$ & $5.0 \pm 0.17$ & $32.5 \pm 51.5$ \\
$\Delta$ SGRQ & $-1.9 \pm 5.2$ & $-5.4 \pm 3.4$ & $-7.1 \pm 4.3$ & $-6.1 \pm 0.1$ \\
$\Delta$ MMRC & $0.5 \pm 0.5$ & $-0.46 \pm 0.21$ & $-0.5 \pm 0.17$ & Not available \\
Atelectasis & 0 & 31 & 9 & 3
\end{tabular}

Data are presented as $\mathrm{n}$ or mean士SEM. CV+: positive collateral ventilation phenotype; $\mathrm{CV}$-: negative collateral ventilation phenotype; $\mathrm{CP}$ : collapse phenomenon phenotype; $\mathrm{FEV}_{1}$ : forced expiratory volume in $1 \mathrm{~s}$; $\mathrm{VC}_{\max }$ maximum vital capacity; RV: residual volume; 6MWT: 6-min walk test; SGRQ: St George's Respiratory Questionnaire; mMRC: modified Medical Research Council dyspnoea scale. 
Finally, two patients were designated as $\mathrm{CV}+$ in their target lobe, both with no clinical response. Fissure analysis was available for one of these patients, showing incomplete fissures with a defect size of $24.9 \mathrm{~cm}^{2}$.

\section{Discussion}

This retrospective analysis is the first to elaborate on the recently recognised collapse phenomenon during collateral ventilation measurements with Chartis $[17,18]$. We report on its frequency and distribution. We present novel information regarding the effects that the ventilation mode used during bronchoscopy has on the appearance of the collapse phenomenon during Chartis assessments. We assess the extent to which Chartis results, especially the collapse phenomenon, correlate with fissure analysis and provide a clinically relevant fissure defect cut-off value, over which collateral ventilation is expected to be registered on Chartis. Finally, our data provide important insights into the clinical significance of the collapse phenomenon.

The collapse phenomenon during Chartis measurements according to our definition [17] is, however, frequently observed in clinical practice and is more prevalent in the lower lobes, as depicted by our findings. In a recent retrospective report of Chartis assessments acquired during spontaneous breathing [38] the frequency of the collapse phenomenon was $18.7 \%$ (78/406 lobes), which compares well with $21.7 \%$ in our spontaneous breathing group. In the report [38] the collapse phenomenon was found almost exclusively in the lower lobes. The collapse phenomenon is most probably the result of the negative pressure indirectly induced distal to the balloon of the activated Chartis catheter. The catheter permits expiration only and prevents inhalation, so that air can only escape but not refill the compartment distal to the balloon through the catheter. The resulting negative pressure obviously is sufficient, at least in some emphysematous individuals, to collapse distal airways with reduced elastic recoil preventing further airflow from the periphery of the target lobe to the Chartis catheter. A similar phenomenon can be observed when bronchoalveolar lavage (BAL) is performed in emphysema patients: active suction causes airway collapse and BAL fluid is trapped in the periphery. It has been observed that the FEV1/FVC ratio is directly proportional to the yield of BAL recovery [39]. In our cohort, however, neither FEV1/FVC ratio nor other pulmonary function test baseline values were significantly different between the collapse phenomenon and other Chartis phenotypes. The higher prevalence of the collapse phenomenon in the lower lobes suggests that, in the context of severe emphysema, the airways in the lower lobes are more prone to instability and collapse than in the upper lobes, a phenomenon that can also be observed frequently during bronchoscopy in the endoscopically accessible central airways of emphysema patients. The reason for this heterogeneous distribution of airway instability remains unknown.

Interestingly, our data demonstrate that Chartis assessment under general anaesthesia and jet ventilation results in increased frequency of the collapse phenomenon. This finding could be attributed to two possible factors. First, under such conditions, the diaphragm is completely relaxed and compresses the lung and the lower lobes in particular. Second, the blockage of the target lobe by the balloon catheter directs inspiratory flow into neighbouring lobes, which inflate and further compress the target lobe during the inspiratory phase of the ventilator. This dual effect might cause airway collapse in the target lobe, preventing airflow from the periphery to the Chartis catheter. During spontaneous breathing, even under moderate sedation, the downward movement of the diaphragm expands target and neighbouring lobes, increasing elastic recoil and maintaining airflow. This observation is significant as it can lead to changes in clinical practice to increase Chartis efficiency. Of course, other forms of ventilation or sedation, e.g. positive pressure ventilation via an endotracheal tube or laryngeal mask in a closed system, might lead to different pathophysiological consequences.

The majority of lobes designated as CP during Chartis assessment showed complete fissures. Lobes designated as $\mathrm{CP}$ with incomplete fissures had significantly smaller fissural defects compared with lobes designated as $\mathrm{CV}+$. This might indicate that the collapse phenomenon is more likely to occur in the context of low or absent collateral ventilation. High collateral ventilation might prevent the dynamic airway collapse by rapidly backfilling the occluded lobe via collateral channels.

In patients with a definitive Chartis phenotype $(\mathrm{CV}+$ or $\mathrm{CV}-)$ the Chartis result correlated well with fissure analysis. This is in accordance with the findings of the European multicentre Chartis trials [14, 15]. However, we did observe a small group of patients with incomplete fissures that had a CV- phenotype when assessed with Chartis. It is, therefore, possible that not all fissure defects readily visible on HRCT are necessarily associated with collateral ventilation. In this context it might be of clinical value to quantify fissural gaps. The method of approximating the defect area used in our study can easily be employed in the clinical routine, especially when the aid of computer-based assessment tools is not available [28]. Our data suggest a defect area of $6.8 \mathrm{~cm}^{2}$ as a clinically important cut-off point that distinguishes fissure defects associated with the existence of registered collateral ventilation. This value shows good specificity, but sensitivity is not optimal and should be further validated in a prospective manner. Our observation that wider fissural gaps result in increased exhaled volumes during Chartis assessment provides further support 
for the notion that fissure defects are primarily responsible for collateral ventilation. However, apart from the size of the defect, it is possible that the extent of emphysematous destruction in close proximity to fissural gaps might also contribute to the magnitude of collateral flow. Finally, we also observed a few patients with complete fissures and a CV+ phenotype, but, as we did not treat these patients with valves, further clinical analysis of this subgroup was not possible.

Both fissure completeness as a surrogate for collateral ventilation and direct measurement of collateral flow with Chartis have disadvantages. Small fissural gaps can be irrelevant to collateral ventilation, whereas collateral ventilation may be present even in patients with seemingly complete fissures in HRCT scans. Moreover, Chartis measurement is a technically demanding procedure, which can result in inconclusive outputs in a proportion of cases. Therefore, we regard both as complementary procedures, mutually compensating for each other's disadvantages with neither of them being superior to the other.

Our findings regarding the clinical significance of the collapse phenomenon constitute another important aspect of our study. Most of the collapse phenomenon patients with complete fissures that received EBV responded well to treatment. However, all of the collapse phenomenon patients with fissure defects treated with valves were nonresponders. When the collapse phenomenon occurs during the assessment of a target lobe, it is recommended to also assess the neighbouring lobe, especially on the left where upper and lower lobes should have the same collateral ventilation status [18]. According to our data, however, measuring the neighbouring lobe frequently also results in the collapse phenomenon, rendering the process inconclusive. Based on our observations, we recommend that in these cases treatment decisions should be based on fissure analysis; patients with the collapse phenomenon and complete fissures in the target lobe should receive EBV treatment, while the collapse phenomenon patients with clinically important fissural defects will probably not respond to treatment.

The current study has certain limitations. One is the retrospective nature of the data analysed, which may introduce selection bias. We performed Chartis assessments in the target and neighbouring lobes as clinically indicated, but not evenly in all four major lobes in all patients. This can cause bias in the data regarding the distribution of Chartis phenotypes among the lobes. Data regarding the influence of ventilation mode on Chartis results are derived from the retrospective comparison of two different patient cohorts at two different time points, not from intra-individual comparison in the same cohort. We believe that prospective studies are required to provide more robust data. Moreover, since we did not treat most $\mathrm{CV}+$ phenotype patients, our study cannot provide comprehensive information about the sensitivity and specificity of Chartis with respect to clinical outcome, in contrast to the European multicentre trials $[14,15]$. Finally, there are slightly different definitions of what constitutes the collapse phenomenon, which limits comparisons with the results of other authors [17, 18, 38].

In conclusion, our findings confirm that the Chartis Pulmonary Assessment System is a valuable tool in planning BLVR procedures, since a definitive Chartis outcome correlates well with fissure analysis and clinical outcome. However, we provide evidence that the collapse phenomenon observed during the assessment of collateral ventilation with Chartis limits its diagnostic yield. Spontaneous breathing should be preferred over jet ventilation to limit the occurrence of the collapse phenomenon during Chartis. The collapse phenomenon should not be mistaken as an absence of collateral ventilation, as patients with the collapse phenomenon in the target lobe have a lower likelihood to respond to valves compared with patients with a collateral ventilation-negative target lobe. When the collapse phenomenon is observed in a target lobe, identifying patients with fissural defects is important, as they may not benefit from EBV treatment and possibly suffer from side-effects. However, the collapse phenomenon patients with complete fissures should be considered for valve treatment.

\section{Acknowledgements}

The authors would like to thank Bernd King (Dept of Radiology, Asklepios Fachkliniken Munich-Gauting, Gauting, Germany) for the acquisition of the HRCT scans.

\section{References}

1 Shah PL, Herth FJ. Current status of bronchoscopic lung volume reduction with endobronchial valves. Thorax 2014; 69: 280-286.

2 Sciurba FC, Ernst A, Herth FJ, et al. A randomized study of endobronchial valves for advanced emphysema. $N$ Engl J Med 2010; 363: 1233-1244.

3 Herth FJ, Noppen M, Valipour A, et al. Efficacy predictors of lung volume reduction with Zephyr valves in a European cohort. Eur Respir J 2012; 39: 1334-1342.

4 Ozmen CA, Nazaroglu H, Bayrak AH, et al. Evaluation of interlobar and accessory pulmonary fissures on 64-row MDCT. Clin Anat 2010; 23: 552-558.

5 Cronin P, Gross BH, Kelly AM, et al. Normal and accessory fissures of the lung: evaluation with contiguous volumetric thin-section multidetector CT. Eur J Radiol 2010; 75: e1-e8. 
6 Koenigkam-Santos $\mathrm{M}$, de Paula WD, Owsijewitsch $\mathrm{M}$, et al. Incomplete pulmonary fissures evaluated by volumetric thin-section CT: semi-quantitative evaluation for small fissure gaps identification, description of prevalence and severity of fissural defects. Eur J Radiol 2013; 82: 2365-2370.

$7 \mathrm{Pu} \mathrm{J}$, Wang Z, Gu S, et al. Pulmonary fissure integrity and collateral ventilation in COPD patients. PLoS One 2014; 9: e96631.

8 van Rikxoort EM, Goldin JG, Galperin-Aizenberg M, et al. A method for the automatic quantification of the completeness of pulmonary fissures: evaluation in a database of subjects with severe emphysema. Eur Radiol 2012; 22: 302-309.

9 Cetti EJ, Moore AJ, Geddes DM. Collateral ventilation. Thorax 2006; 61: 371-373.

10 Davey C, Zoumot Z, Jordan S, et al. Bronchoscopic lung volume reduction with endobronchial valves for patients with heterogeneous emphysema and intact interlobar fissures (the BeLieVeR-HIFi study): a randomised controlled trial. Lancet 2015; 386: 1066-1073.

11 Aljuri N, Freitag L. Validation and pilot clinical study of a new bronchoscopic method to measure collateral ventilation before endobronchial lung volume reduction. J Appl Physiol 2009; 106: 774-783.

12 Mantri S, Macaraeg C, Shetty S, et al. Technical advances: measurement of collateral flow in the lung with a dedicated endobronchial catheter system. J Bronchology Interv Pulmonol 2009; 16: 141-144.

13 Gompelmann D, Eberhardt R, Michaud G, et al. Predicting atelectasis by assessment of collateral ventilation prior to endobronchial lung volume reduction: a feasibility study. Respiration 2010; 80: 419-425.

14 Herth FJ, Eberhardt R, Gompelmann D, et al. Radiological and clinical outcomes of using Chartis ${ }^{\mathrm{TM}}$ to plan endobronchial valve treatment. Eur Respir J 2013; 41: 302-308.

15 Gompelmann D, Eberhardt R, Slebos DJ, et al. Diagnostic performance comparison of the Chartis System and high-resolution computerized tomography fissure analysis for planning endoscopic lung volume reduction. Respirology 2014; 19: 524-530.

16 Klooster K, ten Hacken NH, Hartman JE, et al. Endobronchial valves for emphysema without interlobar collateral ventilation. N Engl J Med 2015; 373: 2325-2335.

17 Gesierich W, Samitas K, Behr J. Determining collateral ventilation during bronchoscopy: unanswered questions. Thorax 2014; 69: 289-290.

18 Shah PL, Herth FJ. Dynamic expiratory airway collapse and evaluation of collateral ventilation with Chartis. Thorax 2014; 69: 290-291.

19 Deslee G, Klooster K, Hetzel M, et al. Lung volume reduction coil treatment for patients with severe emphysema: a European multicentre trial. Thorax 2014; 69: 980-986.

20 Snell G, Herth FJ, Hopkins P, et al. Bronchoscopic thermal vapour ablation therapy in the management of heterogeneous emphysema. Eur Respir J 2012; 39: 1326-1333.

21 Magnussen $\mathrm{H}$, Kramer MR, Kirsten AM, et al. Effect of fissure integrity on lung volume reduction using a polymer sealant in advanced emphysema. Thorax 2012; 67: 302-308.

22 Vestbo J, Hurd SS, Agusti AG, et al. Global strategy for the diagnosis, management, and prevention of chronic obstructive pulmonary disease: GOLD executive summary. Am J Respir Crit Care Med 2013; 187: 347-365.

23 Mahler DA, Weinberg DH, Wells CK, et al. The measurement of dyspnea. Contents, interobserver agreement, and physiologic correlates of two new clinical indexes. Chest 1984; 85: 751-758.

24 Jones PW, Quirk FH, Baveystock CM, et al. A self-complete measure of health status for chronic airflow limitation. The St. George's Respiratory Questionnaire. Am Rev Respir Dis 1992; 145: 1321-1327.

25 Miller MR, Hankinson J, Brusasco V, et al. Standardisation of spirometry. Eur Respir J 2005; 26: 319-338.

26 Wanger J, Clausen JL, Coates A, et al. Standardisation of the measurement of lung volumes. Eur Respir J 2005; 26: 511-522.

27 ATS Committee on Proficiency Standards for Clinical Pulmonary Function Laboratories. ATS statement guidelines for the six-minute walk test. Am J Respir Crit Care Med 2002; 166: 111-117.

28 Reymond E, Jankowski A, Pison C, et al. Prediction of lobar collateral ventilation in 25 patients with severe emphysema by fissure analysis with CT. AJR Am J Roentgenol 2013; 201: W571-W575.

29 Strange C, Herth FJ, Kovitz KL, et al. Design of the Endobronchial Valve for Emphysema Palliation Trial (VENT): a non-surgical method of lung volume reduction. BMC Pulm Med 2007; 7: 10

30 Gesierich W, Weber N, Fertl A, et al. Bronchoscopic assessment of collateral ventilation predicts outcome of endoscopic lung volume reduction with valves. Eur Respir J 2011; 38: Suppl. 55, 3537.

31 Make B, Casaburi R, Leidy NK. Interpreting results from clinical trials: understanding minimal clinically important differences in COPD outcomes. COPD 2005; 2: 1-5.

32 Cazzola M, MacNee W, Martinez FJ, et al. Outcomes for COPD pharmacological trials: from lung function to biomarkers. Eur Respir J 2008; 31: 416-469.

33 Donohue JF. Minimal clinically important differences in COPD lung function. COPD 2005; 2: 111-124.

34 Hartman JE, ten Hacken $\mathrm{NH}$, Klooster $\mathrm{K}$, et al. The minimal important difference for residual volume in patients with severe emphysema. Eur Respir J 2012; 40: 1137-1141.

35 Puhan MA, Chandra D, Mosenifar Z, et al. The minimal important difference of exercise tests in severe COPD. Eur Respir J 2011; 37: 784-790.

36 Crisafulli E, Gorgone P, Vagaggini B, et al. Efficacy of standard rehabilitation in COPD outpatients with comorbidities. Eur Respir J 2010; 36: 1042-1048.

37 Jones PW. St. George's Respiratory Questionnaire: MCID. COPD 2005; 2: 75-79.

38 Herzog D, Thomsen C, Poellinger A, et al. Outcomes of endobronchial valve treatment based on the precise criteria of an endobronchial catheter for detection of collateral ventilation under spontaneous breathing. Respiration 2016; 91: 69-78.

39 Baughman RP. Technical aspects of bronchoalveolar lavage: recommendations for a standard procedure. Semin Respir Crit Care Med 2007; 28: 475-485. 